\title{
Improving the Biodegradability of Non-Biodegradable Compounds Using Photo-Fenton Reaction
}

\author{
Masahiro TOKUMURA*, Rurika HATAYAMA**, Yoshinori KAWASE**, \\ Yukio YANAGISAWA* \\ *Department of Environment Systems, the University of Tokyo, Tokyo 277-8563, Japan \\ **Department of Applied Chemistry, Toyo University, Saitama 350-8585, Japan
}

\begin{abstract}
The feasibility of using the photo-Fenton reaction to improve the biodegradability of non-biodegradable compounds that originated from sewage was examined. Non-biodegradable compounds are degraded by hydroxyl $(\mathrm{OH})$ radicals generated by the photo-Fenton reaction. During the degradation of non-biodegradable compounds, biodegradable intermediates such as organic acids are produced, resulting in improved biodegradability. The results of an experiment, in which a filtered supernatant solution of activated sludge from a sewage treatment plant was used, confirmed that the 5-day biochemical oxygen demand $\left(\mathrm{BOD}_{5}\right)$ increased with decreasing total organic carbon (TOC) concentration as a result of the photo-Fenton reaction. This increased the ratio of $\mathrm{BOD}_{5}$ to $\mathrm{TOC}$, which indicated that the biodegradability was improved. Although many non-biodegradable compounds have electron-dense structures, many biodegradable compounds have electron-lucent structures. Hydroxyl radicals, which are an oxidant in the photo-Fenton reaction, act as an electrophilic agent. In the degradation experiments using a mixture of biodegradable and non-biodegradable compounds, $\mathrm{OH}$ radicals preferentially attacked non-biodegradable compounds, and biodegradable compounds accumulated in the solution. As a result, the biodegradability was improved.
\end{abstract}

Keywords: biodegradability, non-biodegradable compound, photo-Fenton reaction

\section{INTRODUCTION}

The activated sludge process has been widely used for cost-effective wastewater treatment because it has advantages such as low running costs and high degradation efficiency (Lapertot et al., 2006). In the activated sludge process, biodegradable compounds are decomposed by microorganisms in the activated sludge, and non-biodegradable compounds are removed by adsorption onto the surface of the activated sludge (Wilén et al., 2003). Excess sludge is produced with increased biological degradation of biodegradable compounds. In order to reduce the sludge volume, sludge treatment processes such as dewatering, digestion, and burning are carried out (Chu et al., 2009). In the dewatering process, adsorbed non-biodegradable compounds on the sludge desorb and transfer into the liquid phase. As a result, wastewater that includes a large amount of non-biodegradable compounds is produced. Moreover, the digestion process also produces wastewater that includes high concentrations of phosphorus and nitrogen (Ivanov et al., 2009). These wastewaters are returned upstream of the activated sludge process, and are treated along with the raw wastewater (Guo et al., 2010). These wastewaters are called returned water. High loads of non-biodegradable compounds in returned water could inhibit the activated sludge process. This leads to the addition of non-biodegradable compounds into the treated water, and these compounds are discharged into aquatic environments. In fact, some pharmaceuticals, which are classified as non-biodegradable compounds, can be found in aquatic environments (Klavarioti et al., 2009).

Address correspondence to Masahiro Tokumura, Department of Environment Systems, the University of Tokyo, Email: masahiro.tokumura@veritas-sys.jp

Received August 20, 2012, Accepted October 30, 2012. 
Various techniques for degrading non-biodegradable compounds, such as ozonation and $\mathrm{TiO}_{2}$ or $\mathrm{ZnO}$ photocatalytic oxidations, have been examined (Matsumura et al., 2007; Nishio et al., 2006; Pophali et al., 2011). Among these techniques, the photo-Fenton reaction may be a promising technology because of its high oxidation performance (Feng et al., 2005). The photo-Fenton reaction consists of two reactions. The first reaction is the decomposition of $\mathrm{H}_{2} \mathrm{O}_{2}$, catalyzed by $\mathrm{Fe}^{2+}$ (Reaction 1), which generates highly reactive hydroxyl $(\mathrm{OH})$ radicals and oxidizes $\mathrm{Fe}^{2+}$ to $\mathrm{Fe}^{3+}$.

$$
\mathrm{Fe}^{2+}+\mathrm{H}_{2} \mathrm{O}_{2} \rightarrow \mathrm{Fe}^{3+}+\cdot \mathrm{OH}+\mathrm{OH}^{-}
$$

The second reaction is the photoreduction of $\mathrm{Fe}^{3+}$, which occurs on irradiation with ultraviolet (UV) or adequate visible light (Reaction 2).

$$
\mathrm{Fe}^{3+}+\mathrm{H}_{2} \mathrm{O}+h v \rightarrow \mathrm{Fe}^{2+}+\cdot \mathrm{OH}+\mathrm{H}^{+}
$$

In this reaction, $\mathrm{OH}$ radicals are also generated and $\mathrm{Fe}^{3+}$ is reduced to $\mathrm{Fe}^{2+}$. In these two oxidation-reduction reactions of $\mathrm{Fe}$ ions, $\mathrm{OH}$ radicals are continuously produced. Hydroxyl radicals attack pollutants in wastewater, resulting in degradation and mineralization of pollutants via production of intermediates such as organic acids (Katsumata et al., 2006; Wu et al., 2007) (Reaction 3). Because most organic acids are biodegradable (Suarez-Ojeda et al., 2007), the photo-Fenton reaction can decompose non-biodegradable compounds to biodegradable compounds.

$$
\begin{aligned}
& \text { pollutants }+\cdot \mathrm{OH} \rightarrow \text { biodegradable intermediates } \\
& \text { biodegradable intermediates }+\cdot \mathrm{OH} \rightarrow \mathrm{CO}_{2}+\mathrm{H}_{2} \mathrm{O}
\end{aligned}
$$

However, biodegradable compounds such as organic acids have electron-lucent structures (Sakurai and Ikai, 1999). Because OH radicals act as an electrophilic agent, they are not suitable for the degradation of biodegradable compounds. In contrast, because many non-biodegradable compounds have electron-dense structures, $\mathrm{OH}$ radicals are suitable for the degradation of non-biodegradable compounds. A combination of the photo-Fenton reaction and the activated sludge process could therefore be a cost-effective wastewater treatment process. In the combination process, the photo-Fenton reaction is used as a returned water treatment process to improve the biodegradability of non-biodegradable compounds in returned water. As a result of the photo-Fenton reaction, non-biodegradable compounds in the returned water are degraded to biodegradable compounds in the returned water treatment process. Subsequently, biodegradable compounds are degraded by microorganisms in the aeration tank. A schematic diagram of the activated sludge process combined with the photo-Fenton reaction is shown in Fig. 1.

Returned water generally contains high concentrations of phosphorus and nitrogen, originating from the digestion of excess sludge (Ivanov et al., 2009; Guo et al., 2010). High concentrations of phosphorus and nitrogen may affect the photo-Fenton reaction (Wells and Salam, 1968; Fytianos et al., 1998). Because this study is the first step in determining the feasibility of a returned water treatment process using the photo-Fenton reaction, the returned water sample used in the experiment was a filtered supernatant 


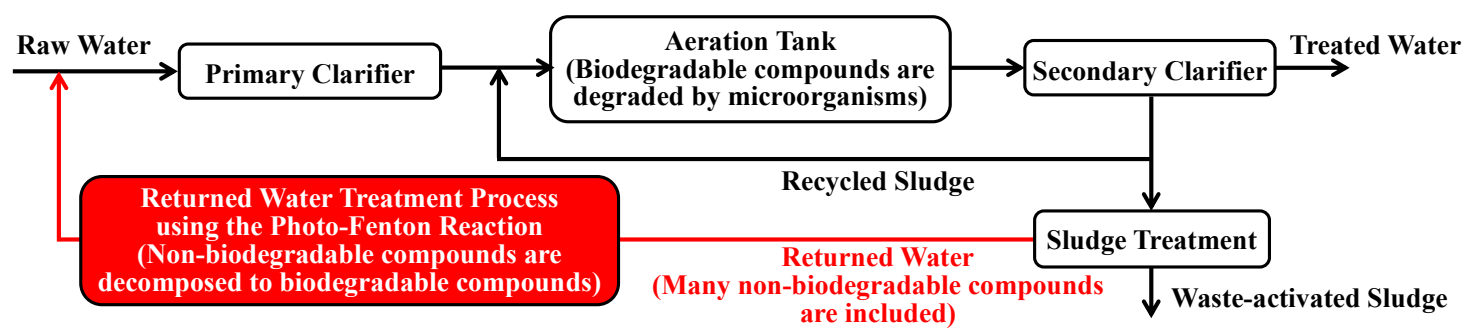

Fig. 1 - Schematic diagram of the activated sludge process combined with photo-Fenton reaction.

solution of activated sludge taken from a secondary clarifier of an effluent treatment plant (Kawagoe City, Saitama, Japan). The samples, therefore, do not contain high concentrations of phosphorus and nitrogen, but include non-biodegradable compounds originating mainly from raw wastewater. The phosphorus and nitrogen concentrations of the supernatant were $2.8 \mathrm{mg}-\mathrm{P} / \mathrm{L}$ and $11 \mathrm{mg}-\mathrm{N} / \mathrm{L}$, respectively. Incidentally, the phosphorus and nitrogen concentrations of the returned water were $68 \mathrm{mg}-\mathrm{P} / \mathrm{L}$ and 537 mg-N/L, respectively (Guo et al., 2010).

\section{MATERIALS AND METHODS Chemicals}

Hydrogen peroxide (30 wt $\%$ ) and Iron(II) sulfate heptahydrate $\left(\mathrm{FeSO}_{4} \cdot 7 \mathrm{H}_{2} \mathrm{O}\right)$ were used as Fenton reagents. Sulfuric acid was used for $\mathrm{pH}$ control before the experiments. All chemicals were reagent grade and purchased from Kanto Chemical Co., Inc. (Tokyo, Japan).

\section{Methods}

The experiments were carried out in a Pyrex glass cylindrical reactor of $0.10 \mathrm{~m}$ diameter and $0.20 \mathrm{~m}$ height. The working volume was $1 \mathrm{~L}$. All experiments were conducted in batch mode at room temperature. A schematic diagram of the experimental setup is shown in Fig. 2. A motor-driven disk-turbine impeller (impeller diameter: $65 \mathrm{~mm}$ ) installed at $0.005 \mathrm{~m}$ above the photoreactor bottom was used at $400 \mathrm{rpm}$ to ensure complete mixing. The UV light irradiation sources were three $15 \mathrm{~W}$ near-UV (black light) fluorescent lamps (FL15T8BLB, Sankyo Electronics, Co., Japan) with a radiation peak at $352 \mathrm{~nm}$. The lamps were located around the cylindrical photoreactor and irradiated the solution externally, as shown in Fig. 2. The distance between the photoreactor wall and the lamps was $0.025 \mathrm{~m}$.

Using sulfuric acid, the solution $\mathrm{pH}$ was adjusted to 3.0, which is the optimal value for photo-Fenton reactions (Tokumura et al., 2006). All experiments were carried out without adding any buffers for $\mathrm{pH}$ adjustments during the degradation process. The $\mathrm{pH}$ monitoring of the initial solution and the samples was performed using a $\mathrm{pH}$ meter (Toa Denpa, Japan).

Samples from the liquid phase were withdrawn using a syringe at predetermined time intervals. In order to remove the fine solids $\left(\mathrm{Fe}^{3+}\right.$ oxyhydroxides, $\mathrm{Fe}$ complexes, etc.), the samples were filtered with a polytetrafluoroethylene-membrane filter with a pore 


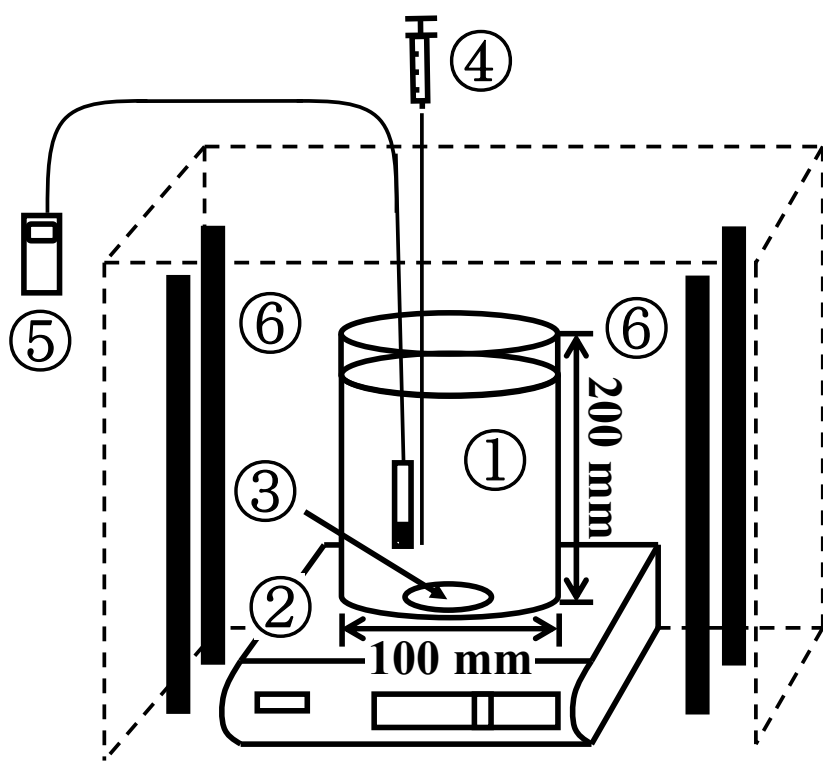

Fig. 2 - Experimental setup (1. photoreactor; 2. magnetic stirrer; 3. stir bar; 4. sampling point; 5. pH meter and thermometer; and 6. ultraviolet lamps).

size of $0.45 \mu \mathrm{m}$ (Advantec Toyo, Tokyo, Japan). The soluble total organic carbon (TOC) was measured using a TOC analyzer (TOC-VE, Shimadzu, Kyoto, Japan).

The Fenton reactions were initiated by the addition of a known amount of $\mathrm{H}_{2} \mathrm{O}_{2}$ to a solution containing Fe(II) sulfate heptahydrate as a source of Fe ion. The starting point of the experiments was set to be the time at which the UV light was turned on and $\mathrm{H}_{2} \mathrm{O}_{2}$ was added to the photoreactor. The $\mathrm{H}_{2} \mathrm{O}_{2}$ concentration was measured using the enzyme method (Sundstrom et al., 1986). The concentrations of $\mathrm{Fe}$ ions $\left(\mathrm{Fe}^{2+}\right.$ and $\mathrm{Fe}^{3+}$ ) dissolved in the solution were measured using the 1,10-phenanthroline method (Sibata Scientific Technology, Ltd., Saitama, Japan) (Tokumura et al., 2006). In the measurement of $\mathrm{Fe}$ concentration, $\mathrm{Fe}^{3+}$ was reduced by ascorbic acid before the reaction with 1, 10-phenanthroline. Then, the total concentration of $\mathrm{Fe}^{2+}$ and $\mathrm{Fe}^{3+}$ was measured. The 5-day biochemical oxygen demand $\left(\mathrm{BOD}_{5}\right)$ was measured according to a standard method (APHA/AWWA/WEF, 1995). Microorganisms present in activated sludge were used as inoculum. Bottles containing the sample solution, mineral nutrition, and inoculum were incubated at $20 \pm 1{ }^{\circ} \mathrm{C}$ in the dark. Five days later, the depletion of dissolved oxygen was measured. A control experiment without a sample solution was conducted in parallel.

Degradation of a mixture of biodegradable and non-biodegradable compounds was carried out to compare their degradation tendencies. In this study, Orange II was used as the non-biodegradable compound and acetic acid was used as the biodegradable compound. Orange II is an azo dye and is used as a typical non-biodegradable compound (Gumy et al., 2005). The initial molar concentrations were adjusted to be equal. 


\section{RESULTS AND DISCUSSION}

Figure 3 shows the typical experimental results for the returned water treatment process using the photo-Fenton reaction. It can be seen from Fig. 3 that the TOC decreases with time; $35 \%$ of the initial TOC was mineralized in $400 \mathrm{~min}$, and thereafter remained constant. During the mineralization of non-biodegradable compounds, organic acids such as acetic acid and oxalic acid are produced. Because organic acids have low electron density structures, they are not adequately degraded by $\mathrm{OH}$ radicals. As a result, organic acids gradually accumulated in the solution with time, and the TOC did not change after $400 \mathrm{~min}$. However, organic acids are classified as biodegradable compounds, and can be degraded using biological treatments. Consequently, the biodegradability of the non-biodegradable compounds in the returned water was improved. The improvement in biodegradability is demonstrated experimentally later in this section.

The $\mathrm{H}_{2} \mathrm{O}_{2}$ concentration decreased linearly with time. As shown in Reaction $1, \mathrm{H}_{2} \mathrm{O}_{2}$ was consumed. In general, the decomposition rate of $\mathrm{H}_{2} \mathrm{O}_{2}$ in the photo-Fenton reaction obeys pseudo-zero-order kinetics (Lee et al., 2003; Tokumura et al., 2011a). This result is in good agreement with the literature.

Although the initial Fe ion concentration was adjusted to $1.3 \mathrm{mg} / \mathrm{L}$, the measured value for the initial $\mathrm{Fe}$ ion concentration was $0.6 \mathrm{mg} / \mathrm{L}$. This may be the result of precipitation of insoluble Fe complexes. Iron ions can easily form complexes with inorganic and organic compounds. Iron hydroxide, which is one of the inorganic Fe complexes, is insoluble. On the other hand, complexes of Fe ions and organic compounds could be degraded by light irradiation (Perez et al., 2006; Tokumura et al., 2011b). Irradiation

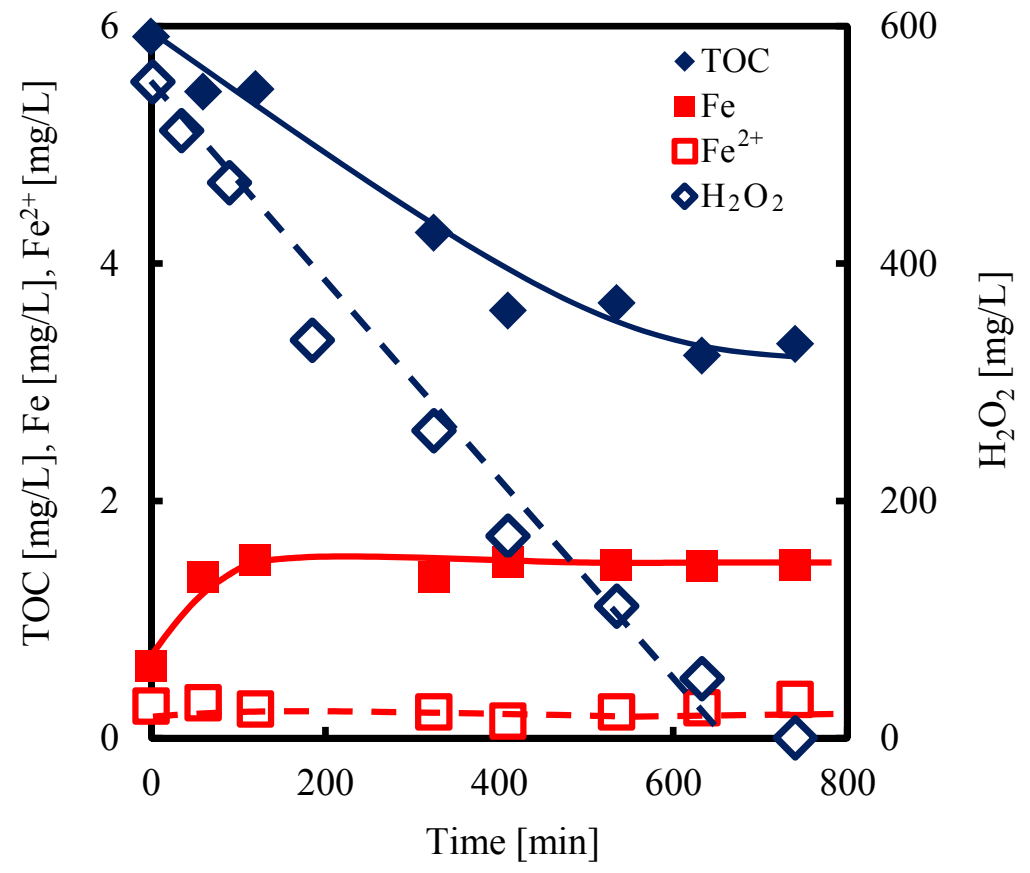

Fig. 3 - Typical experimental results for returned water treatment process using the photo-Fenton reaction (initial $\mathrm{Fe}$ ion concentration $=1.3 \mathrm{mg} / \mathrm{L}$; initial $\mathrm{H}_{2} \mathrm{O}_{2}$ concentration $\left.=500 \mathrm{mg} / \mathrm{L}\right)$. 
with UV light started when the experiment started, and the complexes formed were subsequently degraded. Consequently, Fe ion concentration increased with time and the final Fe ion concentration reached $1.3 \mathrm{mg} / \mathrm{L}$.

In the photo-Fenton reaction, $\mathrm{Fe}^{3+}$ is reduced by Reaction 2 , but the oxidation rate of Reaction 1 is significantly faster than the reduction rate. The $\mathrm{Fe}^{2+}$ produced by Reaction 2 was, therefore, immediately oxidized to $\mathrm{Fe}^{3+}$ by Reaction 1 . As a result, the $\mathrm{Fe}^{2+}$ concentration was very low during the reaction.

\section{Improvement in Biodegradability Using Photo-Fenton Reaction}

In order to avoid the effects of residual $\mathrm{H}_{2} \mathrm{O}_{2}$ on the $\mathrm{BOD}_{5}$ measurements, other experiments to measure the changes in $\mathrm{BOD}_{5}$ during the photo-Fenton reaction were carried out. In these experiments, the initial $\mathrm{H}_{2} \mathrm{O}_{2}$ concentrations were varied from 0 $\mathrm{mg} / \mathrm{L}$ to $500 \mathrm{mg} / \mathrm{L}$. The $\mathrm{BOD}_{5}$ and TOC of each sample were measured after the $\mathrm{H}_{2} \mathrm{O}_{2}$ was exhausted. The duration of each experiment was less than $12 \mathrm{~h}$. The experimental results are shown in Fig. 4.

As seen in Fig. 4, the TOC concentration decreases with increasing initial $\mathrm{H}_{2} \mathrm{O}_{2}$ concentration. The $\mathrm{BOD}_{5}$ decreased with increasing initial $\mathrm{H}_{2} \mathrm{O}_{2}$ concentration up to 77 $\mathrm{mg} / \mathrm{L}$ of $\mathrm{H}_{2} \mathrm{O}_{2}$. When the initial $\mathrm{H}_{2} \mathrm{O}_{2}$ concentration was lower than $77 \mathrm{mg} / \mathrm{L}$, compounds that could be easily degraded by $\mathrm{OH}$ radicals would be preferentially degraded by $\mathrm{OH}$ radicals. The $\mathrm{BOD}_{5}$ and $\mathrm{TOC}$, therefore, decreased significantly at low initial $\mathrm{H}_{2} \mathrm{O}_{2}$ concentrations. At initial $\mathrm{H}_{2} \mathrm{O}_{2}$ concentrations above $77 \mathrm{mg} / \mathrm{L}$, although the

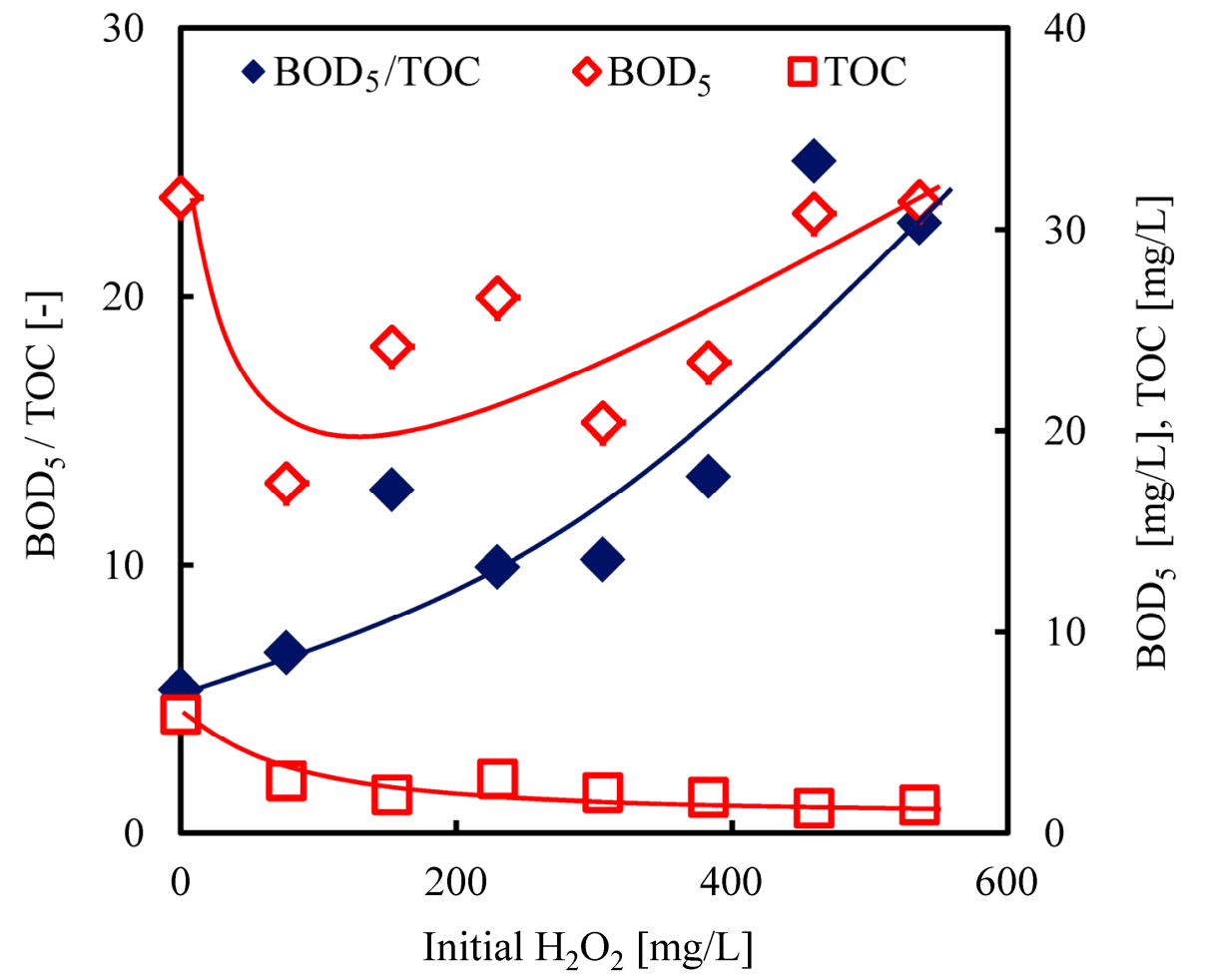

Fig. 4 - Effects of $\mathrm{H}_{2} \mathrm{O}_{2}$ concentration on the improvement in biodegradability (initial Fe ion concentration: $1.3 \mathrm{mg} / \mathrm{L}$ ). 
TOC decreased slightly with increasing initial $\mathrm{H}_{2} \mathrm{O}_{2}$ concentration, the $\mathrm{BOD}_{5}$ increased gradually. One reason may be due to the accumulation of intermediates that are not adequately degraded by $\mathrm{OH}$ radicals, for example, organic acids such as acetic acid and oxalic acid, which have molecular structures of low electron density. As mentioned before, organic acids are classified as biodegradable compounds, therefore, the $\mathrm{BOD}_{5}$ increased with increasing initial $\mathrm{H}_{2} \mathrm{O}_{2}$ concentration. This led to an increase in the $\mathrm{BOD}_{5} / \mathrm{TOC}$ ratio, i.e., the ratio of biodegradable compounds to total organic compounds. This indicates that non-biodegradable compounds were degraded to biodegradable compounds by reaction with $\mathrm{OH}$ radicals.

The value of $\mathrm{BOD}_{5} / \mathrm{TOC}$ obtained in this study was relatively high. This may be attributed to the procedure for the measurement of $\mathrm{BOD}_{5}$. In this study, the value of $\mathrm{BOD}_{5}$ included nitrogenous BOD, as mentioned before. Because a filtered supernatant solution of activated sludge contains a nitrogen component, $\mathrm{BOD}_{5}$ may become higher compared to the value of TOC. Higher nitrogenous BOD value may overestimate the $\mathrm{BOD}_{5} / \mathrm{TOC}$ ratio. Thus, further experiments for the estimation of the effects of nitrogenous $\mathrm{BOD}$ value on the $\mathrm{BOD}_{5} / \mathrm{TOC}$ ratio are required.

\section{Comparison of Degradation Tendencies of Biodegradable and Non-Biodegradable Compounds}

Some non-biodegradable compounds have unsaturated bonds, which have high electron densities. Hydroxyl radicals act as an electrophilic agent and preferentially attack non-biodegradable compounds. Figure 5 displays the experimental results for the

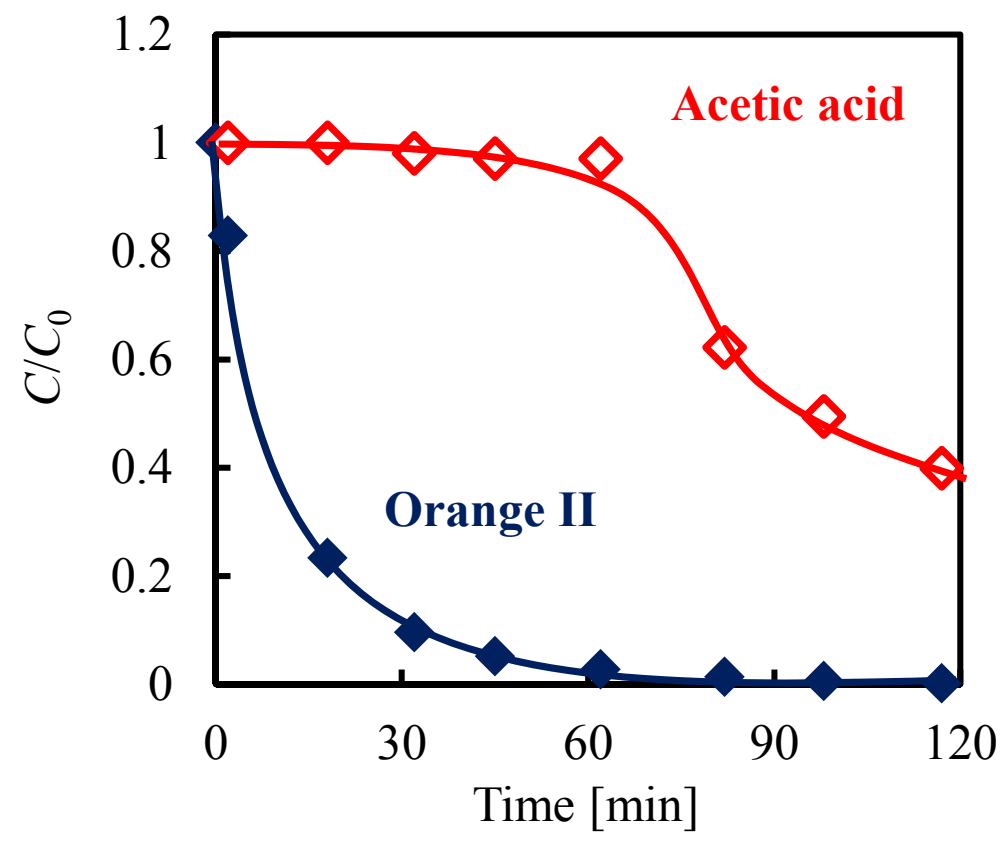

Fig. 5 - Comparison of the degradation tendencies of biodegradable and non-biodegradable compounds [initial $\mathrm{Fe}$ ion concentration $=1.3$ $\mathrm{mg} / \mathrm{L}$; initial $\mathrm{H}_{2} \mathrm{O}_{2}$ concentration $=500 \mathrm{mg} / \mathrm{L}$; initial concentration of biodegradable compound (acetic acid) $=30 \mathrm{mg} / \mathrm{L}(0.5 \mathrm{mM})$; initial concentration of non-biodegradable compound (Orange II) $=175$ $\mathrm{mg} / \mathrm{L}(0.5 \mathrm{mM})]$. 
comparison of the degradation tendencies of a non-biodegradable compound and a biodegradable compound. It can be seen from the figure that although the concentration of the non-biodegradable compound gradually decreases with time, the concentration of the biodegradable compound does not. After the degradation of the non-biodegradable compound was largely complete, the concentration of the biodegradable compound started to decrease. These results were attributed to the different reactivities of the compounds with $\mathrm{OH}$ radicals. The reactivity of Orange II with an $\mathrm{OH}$ radical is $10^{9}$ $\mathrm{L} /\left(\mathrm{mol} \cdot \mathrm{s}\right.$ ) (Yuranova et al., 2004), whereas that of acetic acid is $1.6 \times 10^{7} \mathrm{~L} /(\mathrm{mol} \cdot \mathrm{s})$ (Stefan et al., 1996).

\section{CONCLUSIONS}

This study focused on the enhancement of the biodegradability of non-biodegradable compounds using the photo-Fenton reaction for the effective use of an activated sludge system. The experimental results revealed the following facts.

1. Hydroxyl radicals generated by the photo-Fenton reaction have the ability to convert non-biodegradable compounds into biodegradable compounds. The $\mathrm{OH}$ radicals could also degrade non-biodegradable compounds to $\mathrm{CO}_{2}$ and $\mathrm{H}_{2} \mathrm{O}$.

2. During the photo-Fenton reaction, biodegradable compounds accumulated in the solution. This is attributed to the differences between the reactivities of non-biodegradable compounds and biodegradable compounds with $\mathrm{OH}$ radicals.

This investigation has demonstrated the potential of applying the photo-Fenton reaction to the treatment of returned water. This study was undertaken as a starting point. More verification studies for practical use, such as the effects of phosphorus and nitrogen on the process, are required.

\section{ACKNOWLEDGEMENT}

The authors would like to thank the JSPS Research Fellowships for Young Scientists $(23 \cdot 5773)$.

\section{REFERENCES}

APHA/AWWA/WEF (1995) Standard Methods for the Examination of Water and Wastewater, 19th edn. American Public Health Association/American Water Works Association/Water Environment Federation. Washington DC, USA.

Chu L., Yan S., Xing X. H., Sun X. and Jurcik B. (2009) Progress and perspectives of sludge ozonation as a powerful pretreatment method for minimization of excess sludge production. Water Res., 43(7), 1811-1822.

Feng J., Hu X. and Yue P. L. (2005) Discoloration and mineralization of Orange II by using a bentonite clay-based $\mathrm{Fe}$ nanocomposite film as a heterogeneous photo-Fenton catalyst. Water Res., 39(1), 89-96.

Fytianos K., Voudrias E. and Raikos N. (1998) Modelling of phosphorus removal from aqueous and wastewater samples using ferric iron. Environ. Pollution, 101(1), 123-130. 
Gumy D., Fernández-Ibáñez P., Malato S., Pulgarin C., Enea O. and Kiwi J. (2005) Supported $\mathrm{Fe} / \mathrm{C}$ and $\mathrm{Fe} / \mathrm{Nafion} / \mathrm{C}$ catalysts for the photo-Fenton degradation of Orange II under solar irradiation. Catal. Today, 101(3-4), 375-382.

Guo C. H., Stabnikov V. and Ivanov V. (2010) The removal of nitrogen and phosphorus from reject water of municipal wastewater treatment plant using ferric and nitrate bioreductions. Bioresour. Technol., 101(11), 3992-3999.

Ivanov V., Kuang S., Stabnikov V. and Guo C. (2009) The removal of phosphorus from reject water in a municipal wastewater treatment plant using iron ore. J. Chem. Technol. Biotechnol., 84(1), 78-82.

Katsumata H., Kaneco S., Suzuki T., Ohta K. and Yobiko Y. (2006) Degradation of polychlorinated dibenzo- $p$-dioxins in aqueous solution by $\mathrm{Fe}(\mathrm{II}) / \mathrm{H}_{2} \mathrm{O}_{2} / \mathrm{UV}$ system. Chemosphere, 63(4), 592-599.

Klavarioti M., Mantzavinos D. and Kassinos D. (2009) Removal of residual pharmaceuticals from aqueous systems by advanced oxidation processes. Environ. Int., 35(2), 402-417.

Lapertot M., Pulgarín C., Fernández-Ibáñez P., Maldonado M. I., Pérez-Estrada L., Oller I., Gernjak W. and Malato S. (2006) Enhancing biodegradability of priority substances (pesticides) by solar photo-Fenton. Water Res., 40(5), 1086-1094.

Lee Y., Jeong J., Lee C., Kim S. and Yoon J. (2003) Influence of various reaction parameters on 2,4-D removal in photo/ferrioxalate $/ \mathrm{H}_{2} \mathrm{O}_{2}$ process. Chemosphere, 51(9), 901-912.

Matsumura T., Noshiroya D., Tokumura M., Znad H. T. and Kawase Y. (2007) Simplified model for the hydrodynamics and reaction kinetics in a gas-liquid-solid three-phase fluidized-bed photocatalytic reactor: degradation of $O$-cresol with immobilized $\mathrm{TiO}_{2}$. Ind. Eng. Chem. Res., 46(8), 2637-2647.

Nishio J., Tokumura M., Znad H. T. and Kawase Y. (2006) Photocatalytic decolorization of azo-dye with zinc oxide powder in an external UV light irradiation slurry photoreactor. J. Hazard. Mater., 138(1), 106-115.

Perez M. H., Penuela G., Maldonado M. I., Malato O., Fernandez-Ibanez P., Oller I., Gernjak W. and Malato S. (2006) Degradation of pesticides in water using solar advanced oxidation processes. Appl. Catal. B: Environ., 64(3-4), 272-281.

Pophali G. R., Hedau S., Gedam N., Rao N. N. and Nandy T. (2011) Treatment of refractory organics from membrane rejects using ozonation. J. Hazard. Mater., 189(1-2), 273-277.

Sakurai M. and Ikai A. (1999) Computational Chemistry Primer. Maruzen, Tokyo, Japan. (in Japanese)

Stefan M. I., Hoy A. R. and Bolton J. R. (1996) Kinetics and mechanism of the degradation and mineralization of acetone in dilute aqueous solution sensitized by the UV photolysis of hydrogen peroxide. Environ. Sci. Technol., 30(7), 2382-2390.

Suarez-Ojeda M. E., Guisasola A., Baeza J. A., Fabregat A., Stüber F., Fortuny A., Font J. and Carrera J. (2007) Integrated catalytic wet air oxidation and aerobic biological treatment in a municipal WWTP of a high-strength $o$-cresol wastewater. Chemosphere, 66(11), 2096-2105.

Sundstrom D. W., Klei H. E., Nalette T. A., Reidy D. J. and Weir B. A. (1986) Destruction of halogenated aliphatics by ultraviolet catalyzed oxidation with hydrogen peroxide. Hazard. Waste Hazard. Mater, 3(1), 101-110.

Tokumura M., Morito R., Hatayama R. and Kawase Y. (2011b) Iron redox cycling in hydroxyl radical generation during the photo-Fenton oxidative degradation: 
Dynamic change of hydroxyl radical concentration. Appl. Catal. B: Environ., 106(3-4), 565-576.

Tokumura M., Ohta A., Znad H. T. and Kawase Y. (2006) UV light assisted decolorization of dark brown colored coffee effluent by photo-Fenton reaction. Water Res., 40(20), 3775-3784.

Tokumura M., Sekine M., Morito R. and Kawase Y. (2011a) Decolorization and mineralization of Oolong tea polyphenols in colored soft drink wastewater by photo Fenton reaction. Water Sci. Technol., 63(9), 1894-1898.

Yuranova T., Enea O., Mielczarski E., Mielczarski J., Albers P. and Kiwi J. (2004) Fenton immobilized photo-assisted catalysis through a Fe/C structured fabric. Appl. Catal. B: Environ., 49(1), 39-50.

Wells C. F. and Salam M. A. (1968) Complex formation between iron(II) and inorganic anions. Part II. The effect of oxyanions on the reaction of iron(II) with hydrogen peroxide. J. Chem. Soc. A, 308-315.

Wilén B. M., Jin B. and Lant P. (2003) The influence of key chemical constituents in activated sludge on surface and flocculating properties. Water Res., 37(9), 2127-2139.

Wu D., Liu M., Dong D. and Zhou X. (2007) Effects of some factors during electrochemical degradation of phenol by hydroxyl radicals. Microchem. J., 85(2), 250-256. 